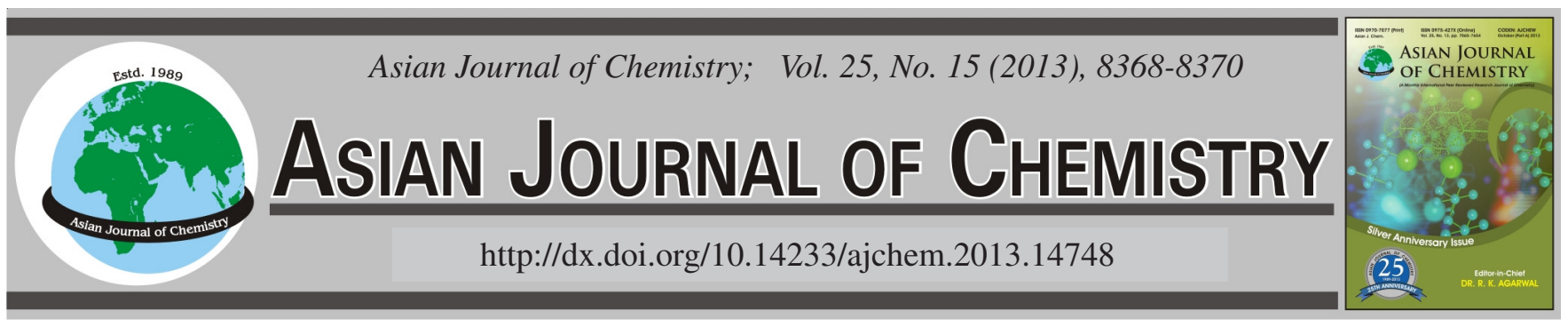

\title{
Ethyl Acetate Extraction Atomic Fluorescence Spectrometric Determination of Trace Silver in Seawater
}

\author{
JiANPING Lu* ${ }^{*}$ HuQUAN Ni and ChaO MaO
}

College of Chemistry \& Chemical Engineering, Guangxi University, Nanning 53004, China

*Corresponding author: Tel: +86 13877141094; E-mail: 1jianpi@hotmail.com

A novel method was developed for indirect determination of trace amount of silver in seawater by ethyl acetate extraction-atomic fluorescence spectrometry (AFS). Based upon the complex, formed among $\mathrm{Ag}^{+}, \mathrm{I}^{-}$and $\mathrm{Hg}^{2+}$ in $0.2 \mathrm{~mol} \mathrm{~L}^{-1}$ of nitric acid and extracted by ethyl acetate, the mercury is determined in terms of silver. The effects of extraction conditions and other factors on the determination were investigated. Under the optimum experimental conditions, the results showed that the linearity located in $0-8 \mu \mathrm{g} \mathrm{mL} \mathrm{m}^{-1}$ silver, the detection limit was 8.8 $\mathrm{ng} \mathrm{mL}^{-1}$ and the relative standard deviation was $1.5-3.5 \%$. The method was applied to determine the trace amount of silver in seawater with recoveries of $99.6-112.0 \%$.

Key Words: Ethyl acetate extraction, Atomic fluorescence spectrometry, Indirect determination, Silver.

\section{INTRODUCTION}

Silver, one kind of highly toxic metals, is susceptible to be absorbed by aquatic organisms. The silver in the water mainly comes from natural weathering, mining, metallurgy, metal processing, electroplating, food processing and film industry activity, etc. ${ }^{1}$. Silver can enter human body through respiratory, digestive system and skin, which causes damage to human's health. WHO suggested that the content of silver should not exceed $0.1 \mathrm{mg} \mathrm{L}^{-1}$ in water, while the United States Environmental Protection Agency recommended that the maximum value be $0.05 \mathrm{mg} \mathrm{L}^{-12}$. Therefore, monitoring silver in environment is very important.

The silver concentration in seawater is very low. In recent years, the main analytical method to determine silver is flame atomic absorption spectrophotometry (FAAS), however, it needs longer pre-concentration procedure. Moreover, its sensitivity, precision and accuracy often can not meet the requirements of the analysis of trace silver ${ }^{3}$. Electrothermal atomic absorbance spectrophotometry (ETAAS) $)^{4-7}$, inductively coupled plasma-atomic emission spectrometry (ICP-AES) ${ }^{8}$ and inductively coupled plasma-mass spectrometry ICP-MS ${ }^{9-13}$ are also reported. These methods are not suitable in application of routine analytical work due to their high price and complex equipment. Although atomic fluorescence spectrometry has unique advantages in determining some elements, there has been no report on atomic fluorescence spectrometric method for determination of silver in literature, since no silver hollow cathode lamp is commercial available. Here, we reported a novel method of determining the $\mathrm{Ag}^{+}$in seawater based upon a complex formed among $\mathrm{Ag}^{+}, \mathrm{I}^{-}$and $\mathrm{Hg}^{2+}$ in $0.2 \mathrm{~mol} \mathrm{~L}^{-1}$ of nitric acid after the complex was extracted by ethyl acetate. The content of silver can be obtained by determining the mercury in the complex. The method has low detection limit, good accuracy, high stability and wide linear range.

\section{EXPERIMENTAL}

The AFS-2202E atomic fluorescence spectrometer (Beijing Haiguang Technology Development Co. Ltd., China) equipped with mercury hollow cathode lamp (General Research Institute for Nonferrous Metals of China) was used to measure the fluorescence intensity emitted from a target element. XS105 Dua Range analytical micro balance (Mettler Toledo, Switzerland) was utilized to obtain sample weight.

Iodine stock solution was prepared by weighing $0.1308 \mathrm{~g}$ $\mathrm{KI}$ in a small beaker, after it was completely dissolved with water and transferred to $100 \mathrm{~mL}$ of brown volumetric flask, diluted to the mark with water. The concentration was $1 \mathrm{mg} / \mathrm{mL}$. Its working standard solution was diluted to $1 \mu \mathrm{g} / \mathrm{mL}$ accordingly. Mercury stock solution was prepared by weighing $0.1715 \mathrm{~g} \mathrm{Hg}\left(\mathrm{NO}_{3}\right)_{2} \cdot 0.5 \mathrm{H}_{2} \mathrm{O}$ as the same manner as iodine solution preparation in $100 \mathrm{~mL}$ of brown volumetric flask. The concentration was $1 \mathrm{mg} / \mathrm{mL}$. Its working standard solution was diluted into $1 \mu \mathrm{g} / \mathrm{mL}$ with water. Volume fraction of $1 \%$ $\mathrm{KBH}_{4}$ was prepared by dissolving $5 \mathrm{~g} \mathrm{NaOH}$ in $1000 \mathrm{~mL}$ of 
volumetric flask with $250 \mathrm{~mL}$ water, adding $10 \mathrm{~g} \mathrm{NaBH}_{4}$ and diluting to the mark with anhydrous ethanol. All reagents for analysis were analytic grade. The water was twice distilled. Mercury iodide solution was prepared by mixing the same volume of $1 \mu \mathrm{g} \mathrm{mL}^{-1}$ mercury stock solution and $10 \mu \mathrm{g} \mathrm{mL}$ iodide stock solution.

\section{General procedure}

Sample preparation: After $20 \mathrm{~mL}$ fresh clear seawater

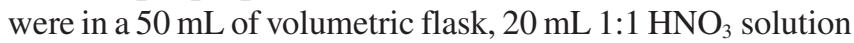
were added for stablizing the sample, then diluted to mark with distilled water. Blank sample was prepared at the same time.

Instrumental scheme: Whole analytical process was monitored by a computer program with intermittent flow injection in Fig. 1; the operation parameters and the procedure were shown in Tables 1 and 2, respectively.

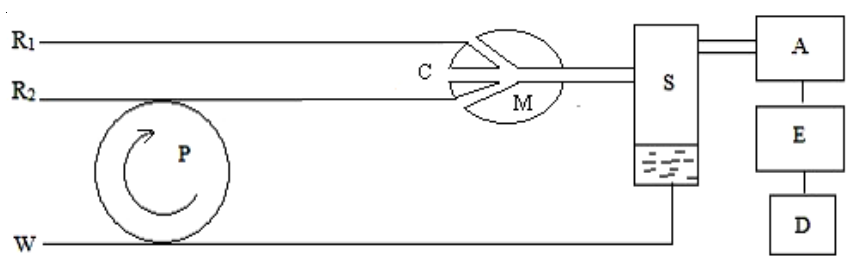

Fig. 1. Schematic diagram of step-flow injection. $\mathbf{R}_{1}$. Reducing agent; $\mathbf{R}_{2}$. sample or current-carrying; P. peristaltic pump; C. carrier gas; $\mathrm{M}$. reactor; S. gas liquid separator; W. waste; A. atomizer; E. detector; D. date processor

TABLE-1

OPERATION PARAMETERS OF AFS-2202E

\begin{tabular}{lc}
\hline \multicolumn{1}{c}{ Instrumental parameter } & Value \\
\hline Negetive high voltage & $270 \mathrm{~V}$ \\
Lamp current & $20 \mathrm{~mA}$ \\
Height of atomizer & $8 \mathrm{~cm}$ \\
Floe rate of carrier gas & $410 \mathrm{~mL} \mathrm{~min}^{-1}$ \\
Shielding gas flow rate & $900 \mathrm{~mL} \mathrm{~min}^{-1}$ \\
\hline
\end{tabular}

\begin{tabular}{ccc} 
& \multicolumn{2}{c}{ TABLE-2 } \\
& INTERMITTENT FLOW PROCEDURE \\
\hline Process & Time (s) & Operation \\
\hline Step 1 & 6 & Preparatory work \\
Step 2 & 12 & Extract the sample \\
Step 3 & 12 & Inject the sample \\
Step 4 & 10 & Delay time 1 s \\
- & - & Reading time \\
\hline
\end{tabular}

Measuremental method: After $4 \mathrm{~mL}$ mercury iodide solution and $2 \mathrm{~mL} \mu \mathrm{g} \mathrm{mL}^{-1}$ silver nitrate solution reacting in $25 \mathrm{~mL}$ colorimetric tube for $5 \mathrm{~min}, 1 \mathrm{~mL}$ nitric acid of $0.2 \mathrm{~mol}$ $\mathrm{L}^{-1}$ was added and diluted to $10 \mathrm{~mL}$ with water. After intensive agitation, the solution was removed into $60 \mathrm{~mL}$ separatory funnel and $5 \mathrm{~mL}$ ethyl acetate was added afterwards. The funnel was shaken for $3 \mathrm{~min}$ and rested for $0.5 \mathrm{~h}$. Then the organic phase was transferred into $10 \mathrm{~mL}$ colorimetric tube and measured by AFS.

\section{RESULTS AND DISCUSSION}

\section{Extraction conditions}

Selections of acidic medium and organic solvents: The concentrations of mercury, iodide and silver were maintained as iodine $20 \mu \mathrm{g} \mathrm{mL}^{-1}$, mercury $2 \mu \mathrm{g} \mathrm{mL}^{-1}$ and silver $2 \mu \mathrm{g} \mathrm{mL}^{-1}$. The aqueous volume was kept as $10 \mathrm{~mL}$. In the condition of 0-0.5 mol L ${ }^{-1}$ nitric acid, $5 \mathrm{~mL}$ isoamyl alcohol, ether, petroleum ether, methyl isobutyl ketone and ethyl acetate were experimented, respectively, to extract the silver mercury iodide complex. It was observed that when the concentration of nitric acid reached to $0.2 \mathrm{~mol} \mathrm{~L}^{-1}$, the extraction by ethyl acetate was similar to that of methyl isobutyl ketone and ether shown in Fig. 2. Considering that ether was easy to volatilize and ethyl acetate did not damage the latex tubing used to aspirate the organic solvent when the determination took place, ethyl acetate was selected to be extraction reagent and the concentration of nitrate acid was $0.2 \mathrm{~mol} \mathrm{~L}^{-1}$.

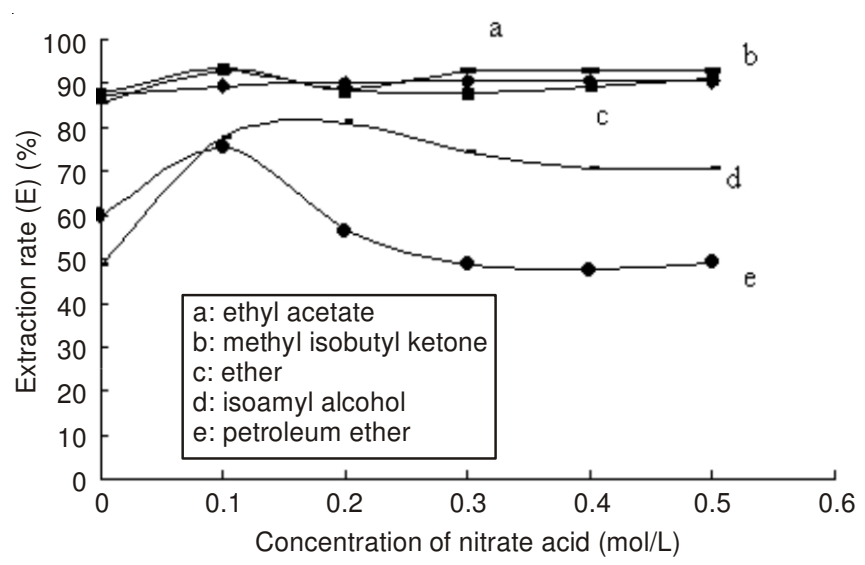

Fig. 2. Effect of aqueous acidity and organic reagents on the extraction efficiency of silver, mercury and iodide complex

Volume of mercury iodide solution: To ensure the $\mathrm{Hg}^{2+}$ in the solution all changing into $\mathrm{HgI}_{4}{ }^{2-}$, the concentration of $\mathrm{KI}$ in the solution should be at least 4 times higher than that of $\mathrm{Hg}^{2+}$ stoichimetrically. Fluorescence intensity was determined with different volumes of mercury iodide. It was found that when the volume of mercury iodide reached $4 \mathrm{~mL}$, the fluorescence intensity tended to be stable in Fig. 3. 4 mL mercury iodide was selected in the method.

Volume of ethyl acetate: The volume of extraction solvent directly impacted on the extraction rate, so it was important to select an appropriate volume. Keeping operation conveniently and without affecting the extraction efficiency, the less organic solvent, the less impact on the environment would be. In the condition that $4 \mathrm{~mL}$ mercury iodide solution, $2 \mathrm{~mL} 1 \mu \mathrm{g} \mathrm{mL}^{-1}$ silver nitrate, $1 \mathrm{~mL} 0.2 \mathrm{~mol} \mathrm{~L}^{-1}$ nitric acid were added into a $10 \mathrm{~mL}$ calorimetric tube and diluted to mark. The experiment was conducted with different volumes of ethyl acetate. It was evident that as the volume of ethyl acetate increased, the extraction rate of silver mercury iodide complex increased in Fig. 4. When the volume of ethyl acetate reached $4 \mathrm{~mL}$, the extraction rate tended to be stable. For operation convenience, the volume of ethyl acetate was selected to be $5 \mathrm{~mL}$ in this method.

Duration of shaking and resting: Before the extraction reached equilibrium, shaking time could directly affect the extraction efficiency. $4 \mathrm{~mL}$ mercury iodide solution, $2 \mathrm{~mL}$ of $1 \mu \mathrm{g} \mathrm{mL}^{-1}$ silver nitrate, $1 \mathrm{~mL}$ of $0.2 \mathrm{~mol} \mathrm{~L}^{-1}$ nitrate acid were mixed and diluted to $10 \mathrm{~mL}$ and then transferred into a $60 \mathrm{~mL}$ separatory funnel with $5 \mathrm{~mL}$ ethyl acetate addition. The 


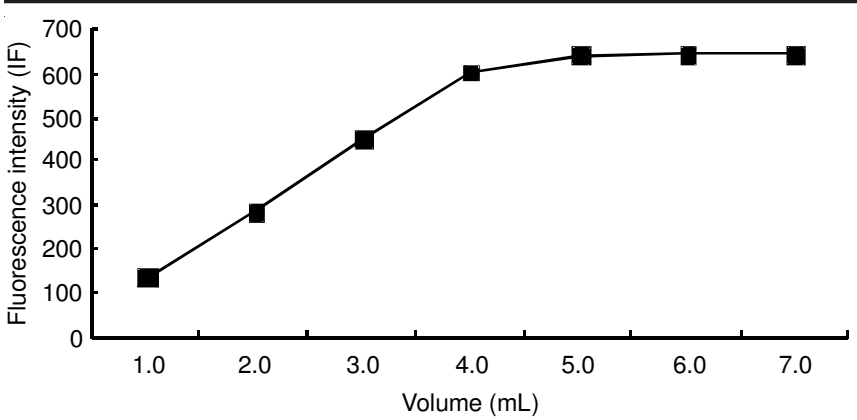

Fig. 3. Effect of mercury and iodide complex amount on the extraction efficiency of silver, mercury and iodide complex

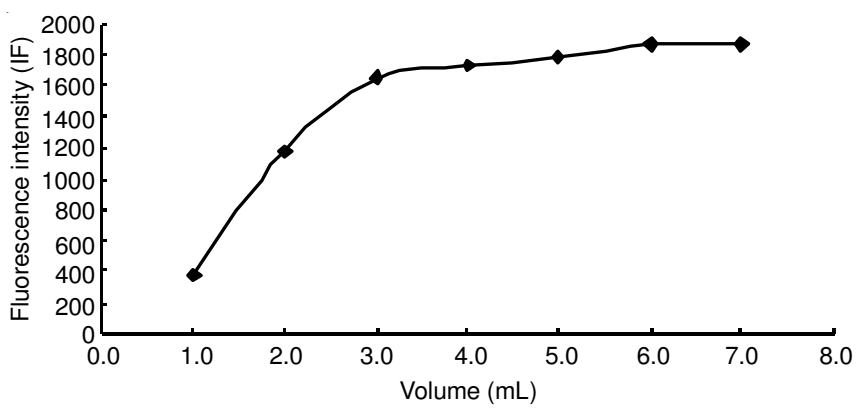

Fig. 4. Effect of ethyl acetate volume on the extraction efficiency of silver, mercury and iodide complex

separatory funnel was oscillated for different times. The results showed that as oscillation time increased, the fluorescence intensity increased. The fluorescence intensity approached stable after $3 \mathrm{~min}$. The oscillation time was selected to be $3 \mathrm{~min}$.

In the same condition, the solution was shaken for $3 \mathrm{~min}$, rested for 10, 20, 25, 30, 35 and $40 \mathrm{~min}$, respectively, its fluorescence intensity was determined. The results showed that as standing time increased, the fluorescence intensity increased and remained stable after $20 \mathrm{~min}$. The standing time was selected to be $0.5 \mathrm{~h}$.

Study of interferences: Interference examination was performed with those common ions which might appeared in the sample. The results showed that 1000 times $\mathrm{Mg}^{2+}, \mathrm{Ca}^{2+}$, $\mathrm{Al}^{3+}, \mathrm{K}^{+}, \mathrm{Zn}^{2+}$ and $\mathrm{Na}^{+}$did not generate interference to $1 \mu \mathrm{g} / \mathrm{mL}$ $\mathrm{Ag}^{+}$standard solution.

When there were 1000 times $\mathrm{Cu}^{2+}$ and $\mathrm{Fe}^{3+}$ in the solution, their interference occurred, however, the amounts of $\mathrm{Cu}^{2+}$ and $\mathrm{Fe}^{3+}$ in the sample were much lower than those added. Therefore, it did not create interference in a real world.

Analytic performance: Different series of concentrations of silver standard solution were determined separately. The relationship between fluorescence intensity and the content of mercury was drawn. The results showed that in the range of 0.01-8 $\mu \mathrm{g} \mathrm{mL}^{-1}$, a good linearity was obtained for silver. For actual samples, the range of $0.01-0.1 \mu \mathrm{g} \mathrm{mL}^{-1}$ was selected as the concentration range of calibration curve for the determination. The linear regression equation was $y=0.6933 \mathrm{x}+$ 66.979 and the correlation coefficient was 0.9905 . Detection limit of this method was $8.8 \mathrm{ng} \mathrm{mL}^{-1}$.
Sample analysis: According to the experimental method, the seawater samples from Beihai, Xiamen in south coast China were obtained, diluted 1000 times and determined. Every sample was determined for 6 times. The results are as shown in Tables 3 and 4.

\begin{tabular}{|c|c|c|c|c|}
\hline \multicolumn{5}{|c|}{$\begin{array}{l}\text { TABLE-3 } \\
\text { DETERMINATION RESULTS OF SILVER } \\
\text { IN CERTIFIED STANDARD MATERIALS }\end{array}$} \\
\hline Sample & Times & $\begin{array}{l}\text { Content } \\
\left(\mu g \mathrm{~L}^{-1}\right)\end{array}$ & $\begin{array}{l}\text { Average } \\
\left(\mu g \mathrm{~L}^{-1}\right)\end{array}$ & $\begin{array}{c}\text { RSD } \\
(\%)\end{array}$ \\
\hline $\begin{array}{l}\text { Beihai } \\
\text { seawater }\end{array}$ & $\begin{array}{l}1 \\
2 \\
3 \\
4 \\
5 \\
6\end{array}$ & $\begin{array}{l}10.47 \\
10.51 \\
10.72 \\
10.47 \\
10.26 \\
10.24\end{array}$ & 10.44 & 1.7 \\
\hline $\begin{array}{l}\text { Xiamen } \\
\text { seawater }\end{array}$ & $\begin{array}{l}1 \\
2 \\
3 \\
4 \\
5 \\
6 \\
\end{array}$ & $\begin{array}{l}10.60 \\
10.38 \\
11.01 \\
11.36 \\
11.26 \\
10.87 \\
\end{array}$ & 10.91 & 3.5 \\
\hline \multicolumn{5}{|c|}{$\begin{array}{c}\text { TABLE-4 } \\
\text { ANALYTIC RESULTS OF RECOVERIES }(n=10)\end{array}$} \\
\hline Sample & $\begin{array}{l}\text { Found } \\
\left(\mu g \mathrm{~L}^{-1}\right)\end{array}$ & $\begin{array}{l}\text { Added } \\
\left(\mu g \mathrm{~L}^{-1}\right)\end{array}$ & $\begin{array}{l}\text { Total found } \\
\left(\mu g \mathrm{~L}^{-1}\right)\end{array}$ & $\begin{array}{c}\text { Recovery } \\
(\%)\end{array}$ \\
\hline Beihai seawater & 10.44 & 10 & 20.40 & 99.6 \\
\hline Xiamen seawater & 10.91 & 10 & 21.35 & 104.4 \\
\hline
\end{tabular}

\section{Conclusion}

A sensitive, fast, simple, practical and low-cost method is developed for determination of silver in seawater. The method is highly selective and good precision as most of the common ions do not interfere. The method should be applicable for the determination of silver in different environment samples.

\section{REFERENCES}

1. J.W.R. Dutton and B.R. Harvey, Water Res., 1, 743 (1967).

2. T.Y. Li, Regeneration Metal, 4, 34 (1986).

3. J. Chen, Yunnan Metallurgy, 41, 57 (2012).

4. D.F. Schutz and K.K. Tnrekian, Geochim. Cosmochim. Acta, 29, 259 (1966).

5. J. Sramkova, S. Kotrly and P. Jakoubkova, Anal. Chim. Acta, 408, 183 (2000).

6. P. Bermejo-Barrera, J. Moreda-Pineiro, A.Moreda-Pineiro and A. Bermejo-Barrera, J. Anal. At. Spectrom., 13, 777 (1998).

7. M.G. Baron, R.T. Herrin and D.E. Armstrong, Analyst, 25, 123 (2000).

8. I. Lopez-Garcia, N. Campillo, I. Arnau-Jerez and M. HernandezCordoba, Spectrochim. Acta B, 58, 1715 (2003).

9. R.P. Singh and E.R. Pambid, Analyst, 115, 301 (1990).

10. K. Ndung'u, M.A. Ranville, R.P. Franks and A.R. Flegal, Marine Chem., 98, 109 (2006).

11. L. Yang and R.E. Ralph, J. Anal. At. Spectrom., 17, 88 (2002).

12. J. Hu, Z. Liu and H. Wang, Anal. Chim. Acta, 451, 329 (2002).

13. C.C. Chang, H.T. Liu and S.J. Jiang, Anal. Chim. Acta, 493, 213 (2003). 